\title{
Effect of Iron Deficiency Anemia on HbA1c in Non-Diabetics
}

\author{
Bansal RK ${ }^{1}$, Yadav $\mathrm{YR}^{2}$, Kulkarni HS ${ }^{1}$, Sonam ${ }^{1}$, Garg $\mathrm{S}^{3}$, Jain $\mathrm{P}^{3}$, \\ Sharma $\mathrm{VK}^{3}$, Maheshwari $\mathrm{S}^{4}$. \\ ${ }^{1}$ Senior Resident, ${ }^{2}$ Assistant Professor, ${ }^{3}$ Resident, ${ }^{4}$ Professor, ${ }^{1,2,3,4}$ Department of Medicine, JLN Medical \\ College, Ajmer, Rajasthan, India; ${ }^{1}$ Dept of Medicine, Navodaya Medical College and research center, \\ Raichur, Karnataka; ${ }^{1}$ SMS medical college, Jaipur.
}

\begin{abstract}
:
Background: Glycated hemoglobin Alc is a well-known indicator of glycemic control in diabetes patients. It comprises of 5\% of total hemoglobin in non-diabetic patients as well. Iron Deficiency Anemia is most common cause of anemia, especially in this part of the world. So, we study the effects of Iron deficiency Anemia on HbA1c levels in non-diabetic adults to determine whether the HbA1c levels increase if any. Methods: A 100 non-diabetic adult patients with Iron Deficiency anemia admitted in various medicine wards and attending OPDs of J.L.N. Medical College and 100 healthy controls were enrolled after fulfilled inclusion and exclusion criteria. Detailed history of clinical examination and biochemical examination was performed including $\mathrm{HbAlc}$. Results: Mean $\mathrm{HbAlc}$ level is more in iron deficient Anemic non-diabetic patients in comparison to non-Anemic non-diabetic patients. Mean HbA1c is $5.01 \pm 0.41$ in control group. While mean $\mathrm{HbAlc}$ level in case group is $6.11 \pm 0.42$. The difference is statistically significant ( $\mathrm{p}$ value $<.001$ ). Conclusion: Iron deficiency Anemia is independent factor affecting HbA1c level in non diabetic patients \& it should be interpreted carefully in all iron deficient anemic patients.
\end{abstract}

Key Words: Iron deficiency anemia,HbA1c,Non diabetics

\section{Introduction}

Glycated hemoglobin A1c (HbA1c) is a major part of $\mathrm{HbA} 1$ and comprises approximately $5 \%$ of the total hemoglobin non-diabetic individuals. It provides a better estimate of average glycemic control than routine determinations of blood glucose concentration and is the most widely used index of chronic glycaemia. The mechanism of glycation involves the non-enzymatic binding of glucose to the N-terminal valine and internal lysine amino groups of hemoglobin. The glycation reaction is mostly irreversible, so that the concentration of $\mathrm{HbA1c}$ is a function of the concentration of glucose to which the erythrocytes are exposed over their lifespan 3 moths (120 days on average). $\mathrm{HbA1c}$ therefore represents a marker of average blood glucose concentration over the previous

Corresponding Author:

Dr.Yad Ram Yadav- Assistant Professor, Department of Medicine, JLN Medical College, Ajmer.

Email-dr.yadram.yadav@gmail.com.
2 to 3months. Glycated-hemoglobin is formed continuously by addition of glucose to the Nterminal of the hemoglobin beta-chain throughout the circulatory life. This process is non-enzymatic and reflects the average exposure of hemoglobin to glucose over a period of nearly 2-3 months. ${ }^{1}$ Glycated hemoglobin has been defined as the fast fraction hemoglobin (HbAla, A1c) which elute first during column chromatography with cation exchange resin. HbA1c levels is affected by not only blood glucose levels alone but also conditions that affect the life span of red blood cells. They are acute or chronic blood loss, thalassemia, sickle cell anemia, hemolytic anemia, hemoglobinopathies, uremia, aplastic anemia, splenectomy, pregnancy, vitamin- B12 and folate deficiency anemia. Falsely elevated $\mathrm{HbA} 1 \mathrm{c}$ concentration can be encountered when there is increased circulating erythrocyte life span. They are alcoholism, hyper bilirubinemia and iron deficiency anemia. According to WHO, iron deficiency is the commonest of all deficiency diseases 
worldwide. Iron deficiency anemia is also the most common in India. Some studies show that HbA1c levels are increased in iron deficiency anemia and attempted to explain based on both modifications to the structure of hemoglobin and levels of $\mathrm{HbA} 1 \mathrm{c}$ in old and new red blood cells. ${ }^{2}$ According to some studies, there were no differences between $\mathrm{HbA} 1 \mathrm{c}$ levels of anemia patients and controls. Study done by El-Agouza L et al showed that HbA1c level were higher in patients with iron deficiency anemia and decreased significantly upon treatment with iron. ${ }^{3}$ Recently Sinha et al showed that HbA1c levels and absolute $\mathrm{HbAlc}$ levels increased with treatment of iron deficiency anemia.4 The results of all these studies are conflicting; hence we were prompted to study the effects of Iron deficiency Anemia on HbA1c levels in Indian non-diabetic adults. Thus, the objective of the present study was to determine whether the HbA1c levels were increased among the patients suffering from iron deficiency anemia without diabetes. If such phenomenon exists, the IDA had to be corrected before taking any significant diagnostic decision based on the increased $\mathrm{HbAlc}$ levels.

\section{Materials \& Methods}

Source of patients-A 100 patients who are diagnosed with Iron Deficiency anemia who are non-diabetics, admitted in various medicine wards and attending OPDs of J.L.N. Medical College and Associated Groups of Hospitals. Among 100 cases 52 were male and 48 were female. 100 persons were taken as control group, among them 56 were male and 44 were female.

Inclusion Criteria: Known cases of Iron Deficiency anemia of age $18-65$ years $(\mathrm{Hb}<13.3 \mathrm{~g} / \mathrm{dl}$ in males, $<12 \mathrm{~g} / \mathrm{dl}$ in females)

Exclusion Criteria: Known cases of Diabetes, Hemoglobinopathy,Chronic liver disease, Chronic kidney disease, Pregnancy and lactation, Malignancies, Chronic Alcoholics, Hyper bilirubinemia, Acute blood loss, Vitamin B12 and folic acid deficiency and Anemia due to causes other than Iron Deficiency.
Quantifying patients were undergoing detailed history, thorough clinical examination and relevant biochemical examination including HbAlc.

\section{LABORATORY METHOD OF ESTIMATION OF HBA1C}

Principle-Latex Agglutination Inhibition Assay: The agglutinator, which consists of synthetic polymer of multiple copies of immune reactive portion of HbA1C, causes agglutination of latex coated with $\mathrm{HbA} 1 \mathrm{C}$ specific mouse monoclonal antibodies. In the absence of $\mathrm{HbA} 1 \mathrm{C}$, agglutinator reagent $\mathrm{HbA} 1 \mathrm{C}$ $\mathrm{R} 2$ and antibody coated micro particles in $\mathrm{HbA} 1 \mathrm{C}$ $\mathrm{R} 1$ reagent will agglutinate leading to increase in absorbance. Presence of HbA1C in sample slows the process of agglutination as it competes with $\mathrm{HbA1C}$ agglutinator leading to less absorbance. An increase in absorbance due to agglutination is measured 700nm and extent of agglutination is used to calculate $\mathrm{HbA} 1 \mathrm{C}$ and is expressed as \% of total HB. Twelve-hours overnight fasting venous blood sample $(5 \mathrm{ml})$ was collected. Potassium EDTA was used as anticoagulant.

\section{Results}

The mean age of patients was $43.39 \pm 18.14$ and control was $42 \pm 18.64$. The mean S. ferritin, S. iron, S.TIBC, \% saturation, in patients were $9.86 \pm 2.67,15.36 \pm 5.82,411.22 \pm 32.48,6.58 \pm 1.56$ and in control group $76.01 \pm 9.03,85.64 \pm 8.04$, $297.6 \pm 28.46$, and $32.44 \pm 5.45$ respectively. These data provide evidence that S. ferritin, S. iron, Transferrin saturation \%, were lower and S.TIBC was higher in anemic patients than in healthy controls and observe difference was statistically significant $(\mathrm{p}<0.001)$ as shown in table. The mean HbA1c level in anemia patients were $6.11 \pm 0.42$ while in control group 5.01 \pm 0.41 .The HbA1c was significantly higher $(\mathrm{p}<0.001)$ in anemic group than control. 
TABLE-1:Comparison of Serum Iron, Serum Ferritin, TIBC, Transferrin Saturation \%, HbA1c, in Cases and Controls.

\begin{tabular}{|l|l|l|c|}
\hline Parameters & $\begin{array}{c}\text { IDA }(\mathrm{n}=100) \\
\text { Mean } \pm \text { SD }\end{array}$ & $\begin{array}{c}\text { Controls }(\mathrm{n}=100) \\
\text { Mean } \pm \text { SD }\end{array}$ & P value \\
\hline Age & $43.39 \pm 18.14$ & $42.51 \pm 18.64$ & - \\
\hline Serum Iron & $15.36 \pm 05.82$ & $85.64 \pm 08.04$ & $<0.001$ \\
\hline Serum Ferritin & $09.86 \pm 02.67$ & $76.01 \pm 09.03$ & $<0.001$ \\
\hline TIBC & $411.22 \pm 32.48$ & $297.6 \pm 28.46$ & $<0.001$ \\
\hline $\begin{array}{l}\text { Transferrin } \\
\text { Saturation \% }\end{array}$ & $06.58 \pm 01.56$ & $32.44 \pm 05.45$ & $<0.001$ \\
\hline HbA1c & $06.11 \pm 0.11$ & $05.01 \pm 0.41$ & $<0.001$ \\
\hline
\end{tabular}

TABLE 2: CORRELATION BETWEEN SERUM IRON AND HBA1C AMONG CASES

\begin{tabular}{|l|l|l|l|}
\hline & $\mathrm{r}-$ value & P value & Significant \\
\hline S. Iron v/s HbA1C & -0.229 & $0.02(\mathrm{~S})$ & Sig \\
\hline
\end{tabular}

Table 2 shows that serum iron level is negatively correlated to HBA1C level in case group with $\mathrm{r}$ value -0.229 and $p$ value 0.02 that is statistically significant. (see Figure 1)

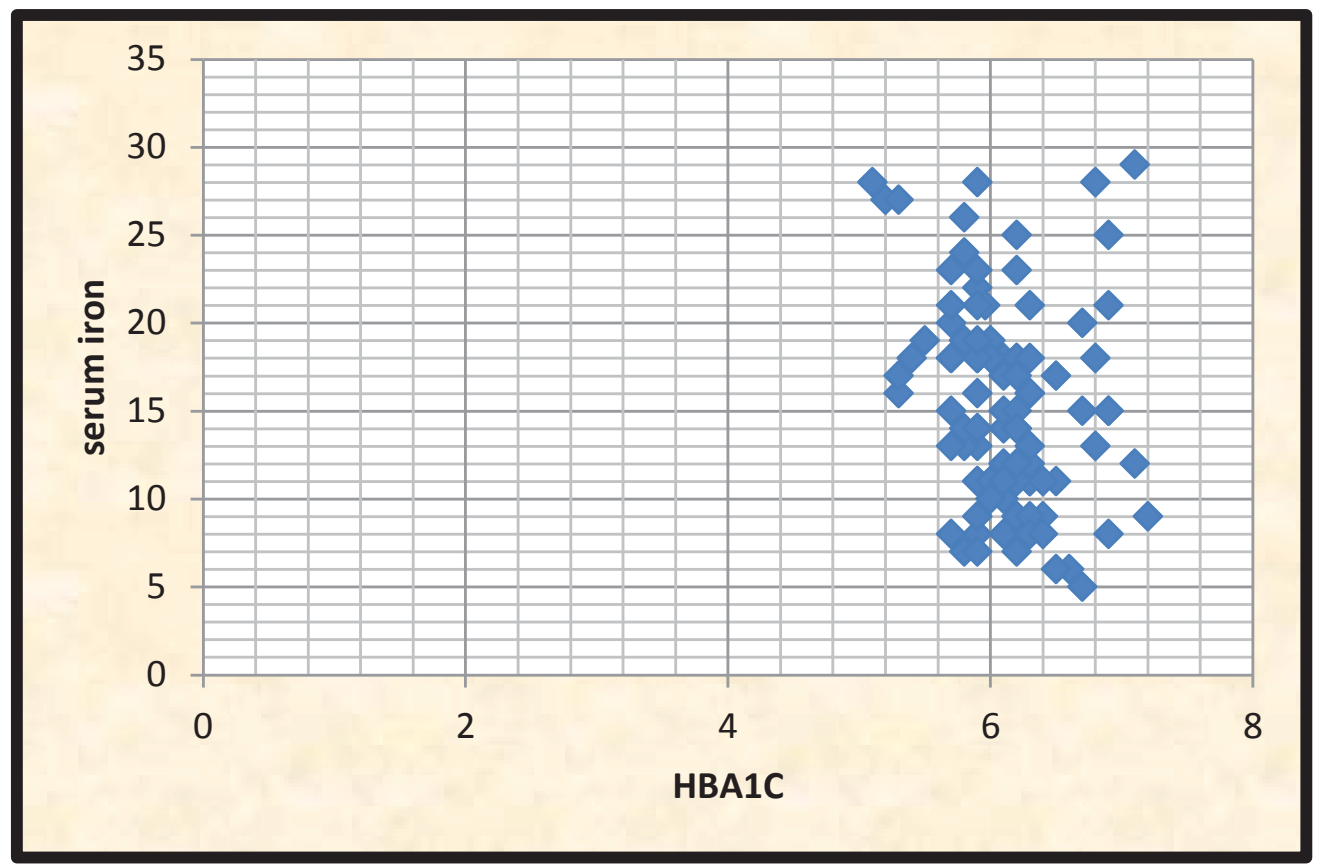

FIGURE 1: CORRELATION BETWEEN SERUM IRON AND HBA1C AMONG CASES 


\section{ORIGINATARTICLE}

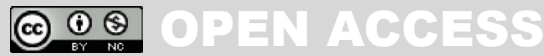

TABLE-3: CORRELATION BETWEEN TIBC AND HBA1C AMONG CASES

\begin{tabular}{|l|l|l|l|}
\hline & r-value & P value & Significant \\
\hline TIBC vs HBA1C & 0.183 & 0.06 & Non-Sig \\
\hline
\end{tabular}

Table 3 shows that serum iron level is positively correlated to HBA1C level in case group with $\mathrm{r}$ value 0.183 and $p$ value 0.06 that is statistically non-significant. (Fi2)

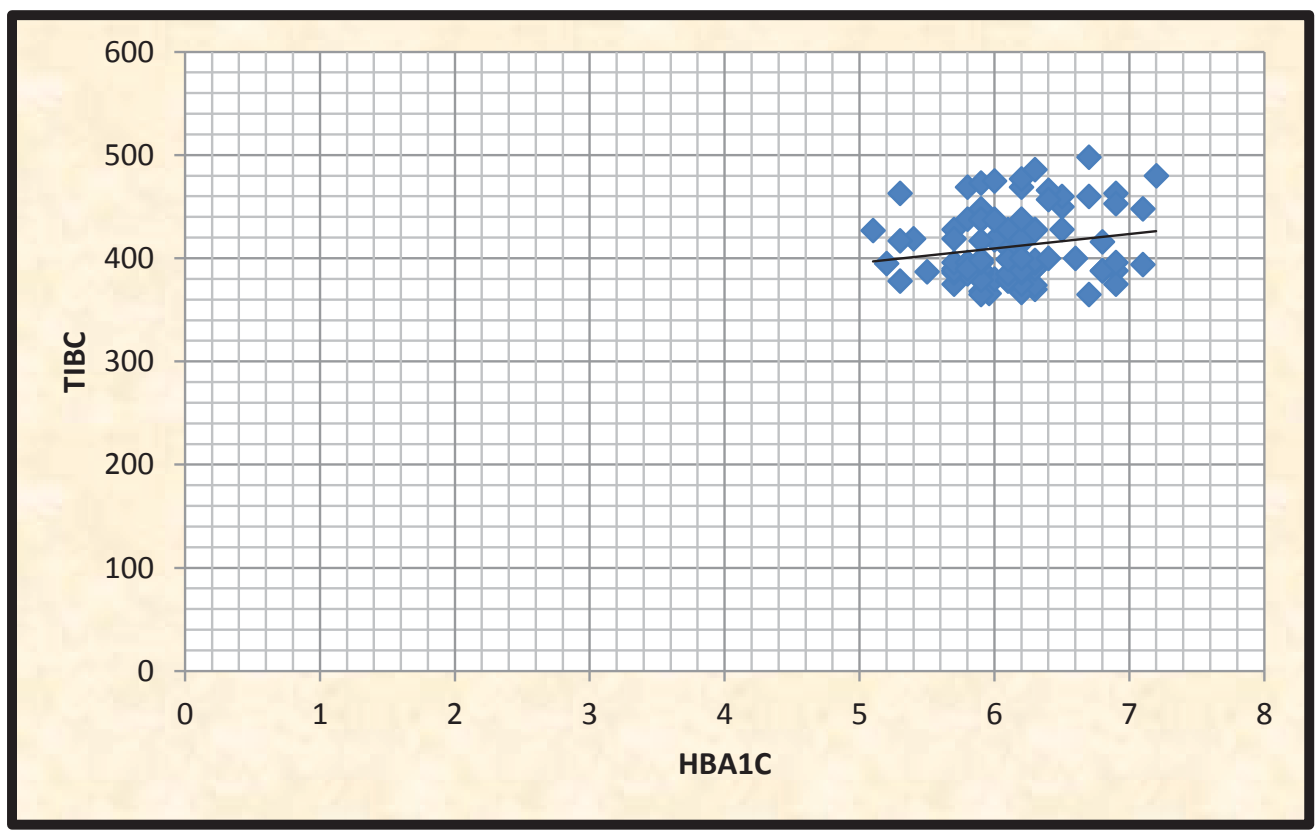

TABLE - 4: CORRELATION BETWEEN \%TRANSFERRIN SATURATION AND HBA1C AMONG CASES

\begin{tabular}{|l|l|l|l|}
\hline & r-value & P value & Significant \\
\hline $\begin{array}{l}\text { \%Tranferrin saturation } \\
\text { vs HbA1C }\end{array}$ & -0.202 & $0.04(\mathrm{~S})$ & Sig \\
\hline
\end{tabular}

Table 4 shows that \% saturation level is negatively correlated to HBA1C level in case group with $\mathrm{r}$ value -0.202 and $p$ value 0.04 that is statistically significant. (Fig 3) 


\section{ORIGTALARTICLE @ $\odot \otimes P B N A C O E S S$}

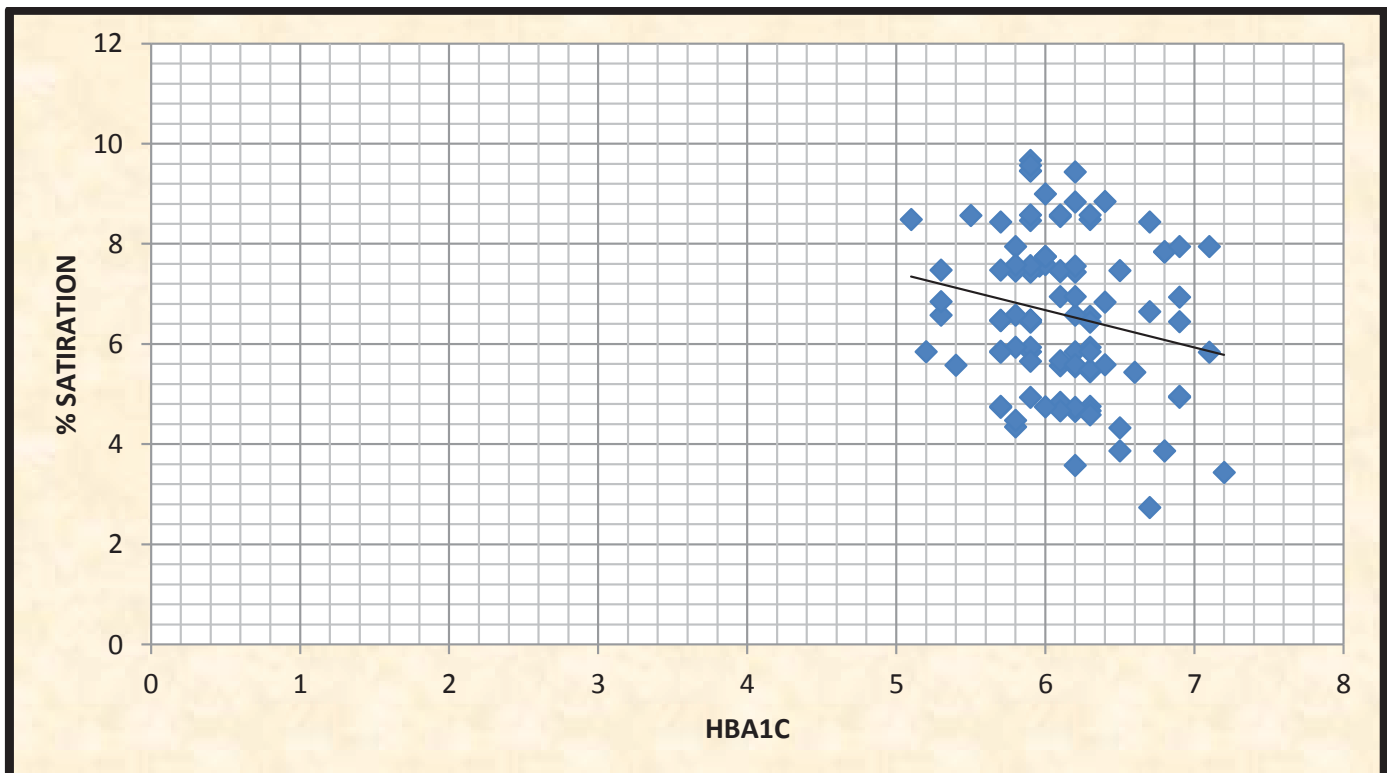

FIGURE 3: CORRELATION BETWEEN \% SATURATION AND HBA1C AMONG CASES

TABLE - 5: CORRELATION BETWEEN FERRETIN AND HBA1C AMONG CASES

\begin{tabular}{|l|l|l|l|}
\hline & r-value & P value & Significant \\
\hline Ferritin vs HBA1C & -0.341 & $0.001(\mathrm{~S})$ & Sig. \\
\hline
\end{tabular}

Table 5 shows that serum ferritin is negatively correlated to HBA1C level in case group with $\mathrm{r}$ value -0.341 and $p$ value 0.001 that is statistically significant. (Fig 4)

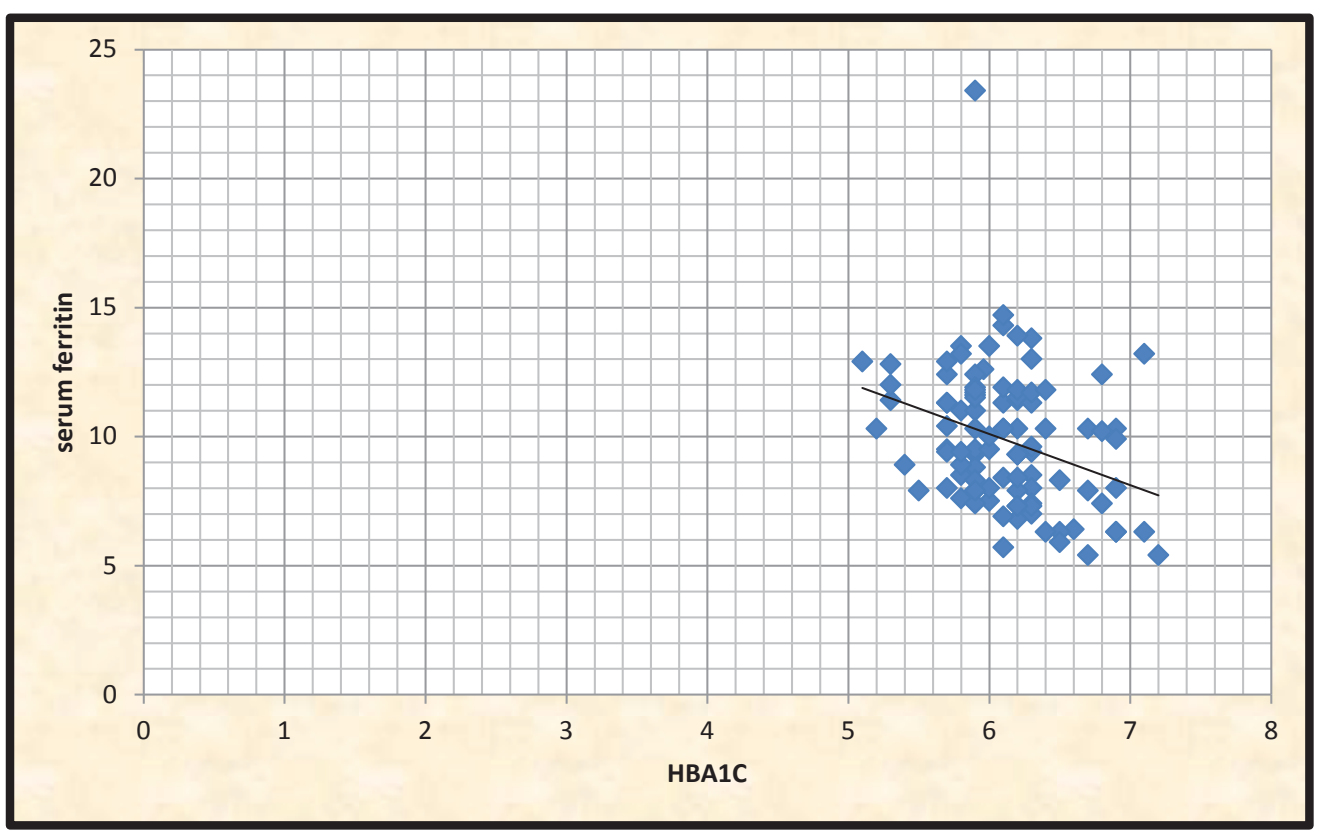

FIGURE 4: CORRELATION BETWEEN FERRETIN AND HBA1C AMONG CASES 
Effect of Iron Deficiency Anemia on Hbalc in Non-Diabetics .... Jour of Diab and Endo Assoc of Nepal 2020; 4 (1): (10-16) ISSN Print 2594-3367 ISSN Online 2631-2107
Journal of Diabetes and Endocrinology Association of Nepal
O RTCNAL A RTCLEE

\section{Discussion}

In our study mean HbA1c level in control group is $5.01 \pm 0.41$ while that mean in case group is $6.11 \pm$ 0.42 with $\mathrm{p}$ value 0.001 . Case (6.11) showed more HBA1c as compared to control (5.01) which give significant result.

Coban $\mathrm{E}$ et al in their study found that mean $\mathrm{HbA} 1 \mathrm{c}$ level of iron deficient Anemic patients was $7.4 \pm$ 0.8 while that in healthy subjects was $5.9 \pm 0.5$ with $\mathrm{p}$ value $<0.001$ which was highly significant.5,6 Patients who had glucose tolerance abnormalities (impaired glucose tolerance or diabetes mellitus), hemolytic Anemia, hemoglobinopathies, chronic renal failure, chronic alcohol ingestion and were excluded from the study. ${ }^{7}$ In patients with IDA, $\mathrm{HbA} 1 \mathrm{c}$ decreased significantly after iron treatment from a mean of $7.4 \% \pm 0.8$ to $6.2 \% \pm 0.6(\mathrm{p}<0.001)$. Tarim et al found that $\mathrm{A} 1 \mathrm{C}$ in iron-deficient patients decreased from $7.6 \pm 2.6$ to $6.2 \pm 1.4 \%$ after iron therapy $(\mathrm{P}<0.05)$, despite similar glucose levels. ${ }^{8,9}$ Shanthi B et al in their study found mean HbA1c level 7.6 \pm 0.5 in iron deficient Anemic patients who were non-diabetic while mean $\mathrm{HbA}$ 1c level in nonAnemic non diabetic subjects was $5.5 \pm 0.8$ with $p$ value $<0.001$ which is statistically significant. ${ }^{10,11,12}$

Several mechanisms have been advocated for increase in levels of glycated hemoglobin in anemic patients. It has been proposed that in IDA, the quaternary structure of the hemoglobin molecule may alter, and so that the Glycation of the $\beta$-globin chains occurs more readily. ${ }^{13}$ According to some investigators, the increase in the glycated hemoglobin levels in non-diabetic anemic patients has been mainly to the decrease in the $\mathrm{Hb}$ levels in these patients (El-Agouza et al., 2002). But these studies the glycation level of other proteins have not been carried out. This study has got a highly relevance because IDA is very highly prevalent in India. $\mathrm{HbA} 1 \mathrm{c}$ is not only affected by the blood sugar levels alone, but also there are various confounding factors especially that of iron deficiency, which is the commonest of the deficiency diseases worldwide. ${ }^{14,15}$ So, IDA must be corrected before making a diagnostic or therapeutic decision on the basis of HbA1c levels.

\section{Conclusion}

In our study we found that Mean HbAlc level is more in iron deficient Anemic non- diabetic patients in comparison to non-Anemic non-diabetic patients. It is $5.01 \pm 0.41$ in control group. While mean $\mathrm{HbA} 1 \mathrm{c}$ level in case group is $6.11 \pm 0.42$. The difference is statistically significant ( $\mathrm{p}$ value $<.001) \mathrm{HbA} 1 \mathrm{c}$ level is shifted to higher range in iron deficient Anemic non-diabetic patients who are having HbAlc level $>5.5$ in comparison to the non-Anemic non-diabetic patients. In iron deficient anemic non-diabetic patients HbAlc level is increased in comparison to the non-anemic patients independent of blood sugar level. So, we concluded that Iron deficiency Anemia is independent factor affecting $\mathrm{HbAlc}$ level in non-diabetic patients \& it should be interpreted carefully in all iron deficient anemic patients.

\section{Reference:}

1. Telen MJ, Kaufman RE. The mature erythrocyte. In: Greer JP, Forester J, et al., editors. Wintrobe's clinical hematology. 11th ed. Lippincot: Williams and Wilkins; 2004. p. 230.

2. Bernstein RE. Glycosylated hemoglobins: hematologic considerations determine which assay for glycohemoglobin is advisable. Clin Chem. 1980;26:174-175.

3. Starkman HS, Wacks M, Soeldner JS, Kim A. Effect of acute blood loss on glycosylated hemoglobin determinations in normal subjects. Diabetes Care. 1983;6:291-294.

4. Horton BF, Huisman TH. Studies on the heterogeneity of hemoglobin. VII. Minor hemoglobin components in haematological diseases. Br J Haematol. 1965;11:296-304.

5. Eberentz-Lhomme C, Ducrocq R, Intrator S, Elion $\mathrm{J}$, Nunez $\mathrm{E}$, Assan $\mathrm{R}$. Haemoglobinopathies: a pitfall in the assessment of glycosylated haemoglobin by ion-exchange chromatography. Diabetologia. 1984;27:596-598. 10. de Boer MJ, Miedema K,

6. de Boer MJ, Miedema K,Casparie AF. 
Glycosylated haemoglobin in renal failure. Diabetologia. 1980;18:437-440.

7. Flückiger R, Harmon W, Meier W, Loo S, Gabbay KH. Hemoglobin carbamylation in uremia. N Engl J Med. 1981;304:823-827.

8. Paisey R, Banks R, Holton R, Young K, Hopton M, White D, et al. Glycosylated haemoglobin in uraemia. Diabet Med. 1986;3:445-448

9. Lind T, Cheyne GA. Effect of normal pregnancy upon the glycosylated haemoglobins. Br J Obstet Gynaecol. 1979;86:210-213.

10. Shendurnikaref N, editor. Iron deficiency is preventable. [Updated on Apr 2007]. http:// www.indiaparenting.com/raisingchild/ data/raisingchild063.shtml.

11. El-Agouza I, Abu Shohla A, Sirdah M. The effect of iron deficiency anaemia on the levels of haemoglobin subtypes: possible consequences for clinical diagnosis. Clin Lab Haematol 2002; 24(5):285-9.
12. Sinha N, Mishra TK, Singh T, Gupta $\mathrm{N}$. Effect of iron deficiency anemia on hemoglobin A1c levels. Ann Lab Med 2012; 32(1):17-22.

13. Coban E, Ozdogan M, Timuragaoglu A. Effect of iron deficiency Anaemia on the levels of hemoglobin A1c in nondiabetic patients. Acta Haematol 2004;112:126-128.

14. Tarim O. Kucukerdogan A, Gunay U, et al, Effects of iron deficiency Anaemia on hemoglobin A1c in type 1 diabetes mellitus. PediatrInt 1999; 41:357-362.

15. Shanthi B, Revathy C, Manjuladevi AJ, shubhashree. Effect of iron defeciency Anaemia on glycation of hemoglobin in nondiabetics. J Clin Diagn 2013 Jan;7(1):15-7. 